УДК 7.036.1

DOI: $10.17223 / 22220836 / 27 / 17$

\title{
И.В. Кудрявцева
}

\section{ТВОРЧЕСТВО ВИКТОРА АРНАУТОВА 1930-х гГ.: ФОРМИРОВАНИЕ ИДЕНТИЧНОСТИ АМЕРИКАНСКОГО ХУДОЖНИКА}

\begin{abstract}
Статья посвящена творчеству Виктора Арнаутова 1930-х г2. и анализу его фрески «Городская жизнь» (1934, башня Койт, Сан-Франщиско). Именно эта работа принесла известность художнику, русскому эмигранту в США и стала одним из знаковых произведений периода Великой депрессии. В статье рассматриваются особенности интеграции Арнаутова в американскую культурную среду, основные тенденции развития калифорнийского искусства 1930-х г2., описываются политические, сочиальные и художественные предпосылки появления фрески «Городская жизнь», а также анализируется опьт «трансплантации» американской идентичности на примере русского художника, включенного в культурный прочесс 1930-х г2. по созданию национального, американского по духу и тематике искусства.

Ключевые слова: Виктор Арнаутов, мурализм, сочиальный реализм, американское искусство, идентичность, 1930-е г2.
\end{abstract}

Виктор Михайлович Арнаутов (1896-1979) - живописец, монументалист, график и скульптор, чья творческая карьера сложилась в эмиграции. Он провел в Сан-Франциско значительную часть своей жизни (без малого 40 лет, с 1925 по 1963 г.), и с Америкой были связаны его становление как художника, а позднее и преподавательская практика. Исследователи американского искусства 1930-х гг. называют Арнаутова одним из лидеров своего поколения и активным участником калифорнийской художественной сцены этого периода. Американское искусство 1920-х - начала 1930-х гг. поглощено поисками оснований для самоидентификации, которые проходят в условиях общего кризиса европейского модернизма межвоенного периода и «ренессанса» мексиканской культуры, опиравшейся на национальные корни.

В рамках статьи попробуем охарактеризовать особенности интеграции художника русского происхождения в американскую культурную среду, выявить показательные проявления тенденций американского искусства в творчестве Виктора Арнаутова, а также описать и проанализировать одно из программных произведений автора - фреску «Городская жизнь» (1934), ставшую негласной эмблемой калифорнийского мурализма периода Великой депрессии.

Следует отметить, что, несмотря на возрождение исследовательского интереса к явлениям и героям русской художественной эмиграции первой половины XX в., многие имена пока остаются без должного внимания. К числу таких художников можно отнести и В.М. Арнаутова. Важными источниками информации на русском языке о жизни и творчестве этого мастера являются его автобиографический очерк «Жизнь заново» [1], записанный журналистом Леонидом Саниным в 1965 г., труды отечественных исследователей Олега Лейкинда и Дмитрия Северюхина, в частности вышедший под их ре- 
дакцией биографический словарь «Художники русской эмиграции» [2]. Большой вклад в сохранение работ Виктора Арнаутова, а также в продвижение и изучение его наследия внес петербургский художник Юрий Иваненко [3]. Среди специализированной литературы на английском языке ${ }^{1}$ следует отметить статью с краткой биографией В.М. Арнутова в сборнике California Art Research [4], представляющем наиболее ярких калифорнийских художников, монографию американского исследователя левого искусства Энтони Ли [5] и диссертацию калифорнийского искусствоведа Сьюзан Ломбарди [6]. В марте 2017 г. в США вышла первая большая монография, посвященная жизни, творчеству и политическому активизму художника [7]. Ее автор, Роберт В. Черный, тщательно собрал фрагменты биографии Арнаутова и снабдил их комментариями, касающимися наиболее неоднозначных и политически резонансных эпизодов. В книге преобладает исторический фокус и практически отсутствует анализ отдельных произведений художника.

Судьба Виктора Арнаутова, как и многих других эмигрантов, уехавших из России в юности или ранней молодости, состоялась за рубежом. Ключевым элементом процесса интеграции художника русского происхождения в новой среде стала учеба. Первоначальные художественные навыки Арнаутов получил еще в гимназическом возрасте в Мариуполе, тогда он брал уроки рисунка и акварели у Василия Петровича Тарасова, мечтал о творческой карьере и готовился к поступлению в Академию художеств. Занятия изобразительным искусством прервались службой в армии, Первой мировой и Гражданской войнами, а также эмиграцией в Китай. В 1921 г. Арнаутов попадает в Харбин, подрабатывает лепщиком барельефов, пишет иконы и расписывает коробки-шкатулки в стилистике Билибина, кроме того, возобновляет свою учебу и начинает посещать занятия в художественной студии «Лотос», где среди его преподавателей были М.А. Кичигин (1883-1968) и А.А. Бернардацци (1871-1921).

В октябре 1925 г. судьба приводит его к берегам западного побережья США. Здесь начинающему художнику представился шанс получить серьезное профессиональное образование, о котором он мечтал с детства. Арнаутов поступил в Калифорнийскую школу изящных искусств (The California School of Fine Arts, CSFA - ныне Художественный институт Сан-Франциско, San Francisco Art Institute, SFAI). В середине 1920-х гг. в школе преподавали выдающиеся калифорнийские художники Джотардо Пьяццоли (Gottardo Piazzoli, 1872-1945) и Ральф Стэкпол (Ralph Stackpole, 1885-1973). В СанФранциско Арнаутов с особым увлечением занимался скульптурой в классе Эдгара Вальтера (Edgar Walter, 1877-1938) и настенной живописью в классе Рея Бойнтона (Ray Boynton, 1883-1951). Последние два года обучения он получал стипендию Анны Бремер и в 1928-1929 выиграл денежную премию за скульптуру «Обнаженная» и фреску «Положение во гроб» для старого собора иконы Пресвятой Богородицы на Фултон стрит, 864 (см.: [4. С. 110]).

В студенческие годы Арнаутов узнает о практике современных мексиканских художников, возрождавших в 1920-е г. технику росписи по сырой штукатурке (итальянская традиция в мексиканской интерпретации). Об ус-

\footnotetext{
${ }^{1}$ Все цитаты из иностранных источников приведены в переводе автора.
} 
пехах и завоеваниях мурализма ${ }^{1}$ начинают говорить в художественной среде Калифорнии. Ральф Стэкпол, лично знакомый с Диего Риверой, посоветовал Арнаутову поехать в Мексику для дальнейшего освоения технологии фресковой живописи под руководством этого ведущего мастера. Временный отъезд в Мексику также помог решить визовые проблемы, появившиеся после завершения курса в CSFA.

Два удивительных, насыщенных года (с 1929 по 1931) провел Арнаутов в качестве ассистента и «ученика» Риверы, приняв участие в создании крупных циклов фресок: «Мексика сквозь века» в Национальном дворце в Мехико (1929-1935), «История Куэрнаваки и штата Морелос» во Дворце Кортеса в Куэрнаваке (1930-1931). Эти росписи демонстрируют характерные и узнаваемые черты авторского почерка Риверы. Знакомство и общение с мексиканским муралистом стало значимым событием для Арнаутова. Его самостоятельные монументальные работы середины 1930-х гг. наследуют композиционные и колористические принципы Риверы, наполнены визуальными цитатами из муралей мастера.

После революции 1917 г. США стали одним из крупнейших центров русской художественной эмиграции. Выходцы из Российской империи нередко выбирали Калифорнию в качестве места для устройства новой жизни. Тем не менее представительного русского сообщества к 1930-м гг. в Сан-Франциско не сформировалось. По свидетельствам историка Р. Черного, численность русских в этот период достигла 7456 человек [7. С. 44], что составляло лишь $1 \%$ от всего населения города. Помимо Виктора Арнаутова русскими по происхождению учениками CSFA в 1920-е гг. были Зигмунд Сазевич (Zygmund Sasevich) и Евгений Иванов (Eugene Ivanoff) (см.: [7. С. 42]). Разобщенность русских художников за границей отмечает отечественный искусствовед Д. Северюхин. Для построения успешной карьеры в условиях новой культурной среды требовалось «преодоление национальной замкнутости» [8. C. 16], в том числе через социальную активность, позволявшую укрепить связи с местным интернациональным художественным сообществом.

За годы учебы, общаясь с разными мастерами, Арнаутов освоил язык современного искусства, «замешанный» на основе различных художественных традиций: академической, реалистической, модернистской, преиспанской. Ощущая свою сопричастность американской художественной школе, Арнаутов включается в профессиональное сообщество Калифорнии и становится его неотъемлемым членом. Примечательно, что во фреске «Аллегория Калифорнии» (1931) Диего Ривера одного из центральных персонажей (сидящий рабочий) наделяет портретными чертами своего «русского ученика». Первая мастерская, которой обзавелся Арнаутов после возвращения из Мексики, располагалась на Вашингтон стрит, 528, неподалеку от известного богемного сквота Montgomery Block, или Monkey Block, заполненного независимыми галереями, студиями для художников и писателей. Здесь в разные годы обитали Марк Твен, Джек Лондон, Джордж Стерлинг, Ральф Стэкпол,

\footnotetext{
${ }^{1}$ Мурализм (от исп. mura - «стена») - термин, обозначающий монументальное искусство, чаще всего употребляется в отношении мексиканского искусства первой половины XX в., однако после распространения популярности фресковой живописи в США и странах Латинской Америки термин «мурализм» приобрел интернациональный характер.
} 
Антон Рефрежье, Рут Крават и многие другие, в 1930-1931 гг. тут останавливался Диего Ривера (см.: [9]). В мастерской Виктора Арнаутова проводились камерные выставки, это место быстро стало точкой притяжения художников, на одной из стен студии на рубеже 1931-1932 гг. он создал фреску с групповым портретом своих друзей и единомышленников ${ }^{1}$.

В это же время Арнаутов стал членом кооператива Art Center, что позволило ему уже в июле 1931 г. организовать первую персональную выставку в Сан-Франциско 2 . Основу экспозиции составили его мексиканские рисунки, акварели и картины, в которых художник часто обращается к изображению национальных героев-типажей: торговок, чистильщиков обуви, носильщиков, рабочих, прачек, мужчин в широкополых сомбреро и женщин с волосами, заплетенными в длинные косы. Несколько работ Арнаутова этого периода хранятся в коллекции Государственного Русского музея: «Мексиканский грузчик», «Продавщица игрушек» и др., часть рисунков находится в Архиве американского искусства института Смитсониан (Archive of American Art, Smithsonian Institution) $)^{3}$, а также в частных коллекциях. Графические работы этой серии сделаны смело, быстрыми и уверенными линиями. Современников произведения Арнаутова удивили отсутствием этнографической экзотики. В рецензии San Francisco Examiner (12 июля 1931 г.) на выставку критик Надя Лаврова пишет: «Арнаутов увидел Мексику русскими глазами... Там, где другие находили причудливые обычаи и буйство цвета, он почувствовал лежащую в основе вековую грусть» (цит. по: [7. С. 76]).

Смотря на мир «русскими глазами», Виктор Арнаутов при этом использовал «оптику», предложенную американским реалистическим искусством. То, что искусствовед Тамара Галеева назвала «расколотым сознанием» [10. С. 61], определяло личность художника на протяжении всей жизни. Однако в 1930-е гг. «американская» составляющая заметно преобладает в жизни и творчестве Арнаутова. Работы этого периода - убедительный пример того, как развивается персональный выразительный язык автора в русле общих тенденций американского искусства. Непосредственное воплощение в творческой стратегии Виктора Арнаутова имели несколько характерных черт, присущих художественной культуре 1930-х гг., таких как интерес к опыту мексиканского мурализма, ставка на реалистическое искусство, а также понимание социальной роли искусства и художника в обществе.

Мурализм, будучи первым оригинальным художественным явлением XX в., рожденным в Новом Свете, становится для американцев примером «альтер-

${ }^{1}$ Среди героев: Паркер Холл, Максин Альбро, Су Вонг, Джулиус Поммер, Михаэль фон Мэйер, Агата Чурчер, Херольд Дин, Брент Карлтон, Дороти Пучинелли, Джанет Ховард, Реймонд Пучинелли, Аделайн Кент, Бэн Каннингем, Жене Клосс, Хелен Форбс, Айлиан Ла-бадт, Марджори Дикенсон, Рут Кревет, Зигизмунд Сазевич, Маргарет Блессингтон, Евгений Иванов и Виктор Арнаутов (см.: [4. С. 112]). Фреска (2,5 х 3,5м) не сохранилась.

${ }_{2}^{2}$ Выставка прошла в галерее Art Center на Монтгомери стрит, 728. Правом проведения выставок обладали члены творческого кооператива, в состав которого входило несколько десятков художников, в том числе Виктор Арнаутов (см.: [7. С. 75]).

3 Archive of American Art, Smithsonian Institution - крупнейшеe собрание документов, произведений искусства, личных архивов художников и исследователей. Основан в 1954 г. Эдгаром П. Ричардсоном. На сегодняшний день существуют исследовательские центры в Вашингтоне и НьюЙорке, а также филиалы в Бостоне, Сан-Франциско, Сан-Марино и Форт-Уэрте. 
нативной формы современности» [11. С. 4], успешным образцом того, как монументальное искусство может быть использовано в формировании национальной идеологии, выражать и программировать нравственные идеалы общества. Социально-политическая атмосфера Соединенных Штатов оказалась решающим фактором для «трансплантации мурализма» 1 в этой стране. В октябре 1929 г. фондовая биржа США рухнула. Начался крупнейший в истории экономики финансовый кризис, получивший название Великая депрессия. Политика нового президента Ф.Д. Рузвельта (1882-1945; президент США с 1933 г.), известная также как «Новый курс» (New Deal), была направлена на восстановление страны и предполагала комплекс реформ, в том числе и в сфере культуры. Государственные программы поддержки культуры были призваны трудоустроить художников и включить искусство в современную повседневную жизнь.

Американцы, опираясь на мексиканский опыт, выбирают путь развития монументального искусства как наиболее эффективного средства общения с широкой аудиторией, выбирают язык реалистического искусства как наиболее доступный и понятный для самого разного зрителя². Закономерно, что искусство Нового курса, по сути государственный заказ, было призвано раскрывать общенациональные темы, отражать повышенный интерес в обществе к рядовому человеку. По словам известного исследователя Эдварда ЛюсиСмита, «Америка - предмет американского искусства 1930-х г.» [12. С. 236]. Художников привлекают темы и сюжеты, связанные с современностью. «Американские сцены» (American scenes) были характерной чертой также риджионализма, однако новому искусству 1930-х гг. присуще особое критическое размышление в противовес идеализации бытовых сюжетов из провинциальной жизни. Таким образом, Великая депрессия создает почву для формирования мощного движения социального реализма.

Государственная политика в отношении культуры шла по пути социальных компромиссов, делая ставку на «искусство для масс». Прагматичность американской культуры рождала «практичное» и «социально полезное» искусство [13], доступное повсюду: школы, почтовые отделения, магазины и пр. Экономический кризис способствовал политизации американского культурного сообщества, симпатия и обращение к левым идеологиям провоцировали рост самосознания и солидарности художников с рабочими.

Произведение, которое принесло широкую известность Виктору Арнаутову и до сих пор является его визитной карточкой, - монументальная фреска «Городская жизнь» из комплекса росписей, украшающих мемориальную башню Койт ${ }^{3}$. К участию в проекте были приглашены 26 художников

\footnotetext{
${ }^{1}$ Термин предложен искусствоведом Франсиско Рейесом Пальма (цит. по: [11. С. 2]).

${ }^{2}$ Возрождению реализма в искусстве США предшествовало творчество художников Ашканской школы (Ashcan school), или «Школы мусорных ведер», среди которых Роберт Генри, Джон Слоан, Эдвард Хоппер, Эверетт Шинн и др. Художники тематизировали повседневную жизнь беднейших рабочих кварталов Нью-Йорка, делая своими героями беспризорников, проституток, иммигрантов и пр.

3 Башня Койт (Coit Tower, Lillian Coit Memorial Tower) располагается на вершине Телеграф Хилл в Сан-Франциско. Построена в 1933 г. в стиле ар деко по проекту архитектора Артура Брауна Младшего (Arthur Brown J., 1874-1957) на деньги, завещенные Лиллиан Хичкок Койт (Lillian Hitchcock Coit, 1843-1929) для сооружения мемориала в честь погибших во время землетрясения 1906 г. пожарных. Высота башни составляет 64 метра. Оформление башни фресками стало
} 
и 19 ассистентов ${ }^{1}$. Руководить ходом работ доверили одному из самых опытных калифорнийских монументалистов на тот период - Виктору Арнаутову 2 . Художники сообща определили единый масштаб и палитру всех муралей. Работа в башне велась 6 месяцев с января по июль 1934 г.

Мураль Арнаутова «Городская жизнь» располагается на центральной стене первого этажа (3 x 11 метров) и представляет собой стилизацию центра оживленного современного Сан-Франциско. Архитектура башни диктует специфику восприятия фрески, которая оказывается расположена достаточно близко к зрителю, что создает эффект соучастия.

С одной стороны, художник создает довольно конкретный образ крупного американского города 1930-х гг. Тщательная работа над деталями и прочная связь с натурой, о чем свидетельствуют подготовительные эскизы [15], позволяют достичь практически документальной точности, что в конечном счете создает убедительную атмосферу современности.

С другой стороны, «Городская жизнь» Арнаутова может быть представлена как квинтэссенция личного опыта автора, примеряющего на себя американскую идентичность художника. Панорама Сан-Франциско, которую мы видим на фреске, сконструирована вокруг перекрестка улиц Монтгомери и Вашингтон, центра неформальной художественной жизни, в это единое пространство автор заключает знаковые достопримечательности, расположенные в разных частях города, среди которых здание муниципалитета, центральной библиотеки (ныне Музей азиатского искусства), Фондовой биржи. На первом плане изображены несколько ключевых персонажей, «выступающих» из общей толпы, один из них - высокий молодой человек в шляпе у газетного киоска, автопортрет В. Арнаутова. Показательно, что художник изображает себя в эпицентре американской городской жизни, он предстает одним из действующих лиц западного современного общества. Этому герою, как изображенным в качестве «скрытых автопортретов» на фресках итальянских мастеров Возрождения, удается балансировать между находимостью внутри композиции и отрешенностью от всего происходящего. Статичная уверенная поза персонажа, пристальный взгляд, обращенный к зрителю, будто замедляют ритм города, подчеркивая его позицию отстраненного наблюдателя.

Автор «Городской жизни» виртуозно использует композиционные приемы, разработанные Д. Риверой, в частности особую «динамическую симметрию» ${ }^{3}$, при которой большие объемы остаются уравновешенными и стабильными, а отдельные фрагменты пронизаны волнообразным ритмом форм и

результатом деятельности первой федеральной художественной программы - Проекта публичных художественных работ (The Public Works of Art Project, PWAP).

${ }^{1}$ После старта PWAP в Сан-Франциско был назначен ответственный за подбор художников, им стал директор Музея де Янга Вальтер Хейл (Walter Heil, 1890-1973). Общая тема цикла фресок современная жизнь Калифорнии. Росписи украшают два этажа, лобби и лестницу (см.: [14])

${ }^{2}$ Помимо ранних опытов и студийной фрески в мастерской, в 1932 г. по заказу доктора Рассела Ли художник создал мурали «Первобытная и современная медицина» в медицинском центре в Пало Альто

${ }^{3}$ Подробно с точки зрения композиции фреску «Городская жизнь» анализирует американский искусствовед и историк Франсис О’Коннер [16], называя Арнаутова самым последовательным учеников Риверы. 
колорита. Все это позволяет муралисту создать гармоничную и визуально разнообразную фреску.

Публичное искусство Калифорнии 1930-х гг. вовлечено в социальные и политические дебаты [5]. История росписей башни Койт сопряжена с трагическими событиями рабочей стачки в мае 1934 г., после которой на фресках В. Арнаутова появляются изображения журналов левого толка New Masses, Daily Worker, The Argonaut, а в работах Б. Закхейма, К. Уайта и Д. Лайнглея - ряд символов и атрибутов, не согласованных с заказчиками. Самым противоречивым стало изображение серпа и молота, из-за которого открытие комплекса было задержано на несколько месяцев.

Во второй половине 1930-х гг. Арнаутов продолжает карьеру муралиста, создает крупные циклы фресок в Сан-Франциско: «История Джорджа Вашингтона», «Деятельность армии в мирное время», а также несколько росписей почтовых отделений по всему штату. Однако «Городская жизнь» в башне Койт выделяется среди прочих монументальных произведений автора, остается программной не только для Арнаутова, но и для всего калифорнийского искусства периода Великой депрессии. Критик Эвелин Силей в Literary Digest (1 августа 1934г.) назвала этот комплекс «самым выдающимся произведением, созданным в рамках PWAР» (цит. по: [7. С. 95]). Мастерское использование традиций мексиканского мурализма и умеренная социальная острота произведений дали Арнаутову точно попасть в контекст общей проблематики калифорнийского искусства своего времени. Успех художника складывался также благодаря его оригинальному «русскому взгляду», позволявшему особо остро переживать трагическое, раскрывая критический смысл социального реализма.

Художественную политику Рузвельта республиканцы сравнили с «красными гнездами» (red nests), заполненными коммунистами» [13. С. 15]. Во время холодной войны это отношение к искусству 1930-х гг. стало преобладающим. Конструирование американской идентичности в послевоенные годы строилось на материале абстрактного экспрессионизма, завоевания социального реализма были оставлены в прошлом. Такая радикальная смена курса в искусстве разочаровывала Арнаутова, он всегда высоко ценил реалистические традиции: «Я не отрицаю важность Пикассо и современных абстракционистов, но я рассматриваю их живопись как лабораторную работу. Их позиция в первую очередь аналитическая. Сегодня у нас нет времени на анализ. Наступила пора нам приступить к синтезу»1.

В конце 1930-х гг. Виктор Арнаутов становится активным участником Русско-американского общества, с 1938 г. членом Коммунистической партии США, на протяжении 1940-х гг. ведет деятельность по поддержке СССР во Второй мировой войне. В своих поздних интервью художник вспоминает: «Зачастую тоска по родным местам охватывала меня с такой силой и властностью, что я готов был уехать немедленно. Но обстоятельства побеждали меня» [1. С. 13]. Одновременно с карьерой художника и активиста Арнаутов начинает преподавательскую деятельность, с 1933 по 1939 г. работает в SFAI, позже получает предложение из Стенфордского университета. В начале 1960-х гг. он не раз возвращался к мысли вернуться на родину:

\footnotetext{
${ }^{1}$ Интервью В. Арнаутова журналу Cronicle от 1 сентября 1935 г. (цит. по: [4. С. 120]).
} 
«В Америке я чувствовал себя незваным гостем, которого терпели, но которому никто не рад. <...> Я осознал, что жить и думать в рамках американского стандарта мышления не могу» [1. С. 22].

Своеобразная «трансплантация» американской идентичности русскому по происхождению художнику Виктору Арнаутову совпала с периодом середины 1930-х гг., солидарность тенденциям эпохи позволила молодому муралисту почувствовать себя сопричастным американской жизни и ее идеалам. Этот эффект оказался недолгим, а новый атрибут личности «не прижился» безоговорочно. В 1963 г. художник возвращается в СССР и получает советское гражданство. Однако несмотря на новый статус, Арнаутова на родине продолжают воспринимать американцем. Так, его имя упоминается в монографии Андрея Чегодаева [17], советский зритель знакомится с работами художника на выставке американского искусства в ГМИИ [18].

Автобиографический очерк Виктора Арнаутова получил название «Жизнь заново», начинать все с чистого листа художнику доводилось нередко, и всякий раз ему удавалось адаптироваться и реализовываться. Так произошло и в 1930-е гг. в США, когда художник Арнаутов в силу своего таланта, профессионализма, художественной чуткости смог стать одним из творцов нового американского по духу и тематике искусства.

\section{Лuтература}

1. Виктор Арнаутов. Жизнь и творчество / авт.-сост. Ю.М. Иваненко. СПб. : СО ЛО СФК, 2007. $80 \mathrm{c}$.

2. Лейкинд О.Л. Художники русской эмиграции (1917-1941): Биографический словарь / О.Л. Лейкинд, Д.Я. Северюхин. СПб. : Изд-во Чернышева, 1994. 587c.

3. Иваненко Ю.М. Жизнь и творчество художника Виктора Арнаутова // Деятели американской культуры из Российской империи. СПб., 2009. С. 19-31.

4. California Art Research / editor Gene Hailey. San Francisco: s.n., 1936. Vol. XX. P. 148 p.

5. Lee A.W. Painting on the Left. Diego Rivera, Radical Politics, and San Francisco's Public Murals. Berkeley : University of California Press, 1999. 284 p.

6. Lombardi S.W. Politics and Humanism in the Depression Era Frescoes of Victor Arnautoff : MA tesis / Suzanne Woodbury Lombardi; University of California. Berkeley, 1984. 212 p.

7. Cherny Robert W. Victor Arnautoff and the Politics of Art. Chicago : University of Illinois Press, 2017. 320 p.

8. Северюхин Д. Русская художественная эмиграция. 1917-1939. СПб. : Изд-во Н.И. Новикова, 2003. $132 \mathrm{c}$.

9. Smith H. The Monkey Block: The Art Culture of the New Deal in San Francisco Bay Area [Электронный ресурc]. 2011. URL: http://www.foundsf.org/index.php?title=The_Monkey_Block (дата обращения: 21.07.2017).

10. Галеева T.A. Джон Грэхем (Иван Домбровский) и абстрактное искусство Америки 1930-х годов // Деятели американской культуры из Российской империи. СПб., 2009. С. 61-65.

11. Indych-López A. Muralism without walls: Rivera, Orozco and Siqueiros in The United States, 1927-1940. Pittsburgh : University of Pittsburgh Press, 2009. 352 p.

12. Lucie-Smith E. Art on the 1930s. The age of anxiety. New York : Rizzoli International publications, $1985.264 \mathrm{p}$.

13. Bustard B.I. A New Deal for the Arts. Seattle : University of Washington Press, 1997. 144 p.

14. Zakheim M. J. Coit Tower San Francisco. It's History and Art / Masha J. Zakheim. San Francisco: Volcano Press, 2009. 136 p.

15. Victor Mikhail Arnautoff papers, Archive of American Art, Smithsonian Institution, reels 3429-3430. 
16. O'Connor F.V. La influencia de Diego Rivera en el arte de los Estados Unidos durante los años treinta y posteriores // Diego Rivera. Retrospectiva. México, D.F. : Ministerio de Cultura, Dirección General de Bellas Artes y Archivos, Centro Nacional de Exposiones, 1987. P. 167-194.

17. Чегодаев А.Д. Искусство Соединенных Штатов Америки. 1675-1975. Живопись. Архитектура. Скульптура. Графика. М. : Искусство, 1976. 204 с.

18. Выставка произведений американского искусства: каталог. М. : Гос. музей изобразительных искусств им. А.С. Пушкина, 1959.

Kudriavtseva Irina $\boldsymbol{V}$. Ural Federal University (Yekaterinburg, Russian Federation).

E-mail: invelian@yandex.ru

Tomsk State University Journal of Cultural Studies and Art History, 2017. № 27. 182-191 pp. DOI: $10.17223 / 22220836 / 27 / 17$

CREATIVITY OF VICTOR ARNAUTOFF IN THE 1930s : IDENTITY FORMATION OF THE AMERICAN ARTIST

Key words: Victor Arnautoff, muralism, social realism, American art, identity, 1930 s

The article is devoted to the early period of Victor Arnautoff's creativity and his fresco "City Life" (1934, Coit Tower, San Francisco). This mural became one of the iconic works of the Great Depression and brought the fame to the author, Russian emigrant in the USA. In this period American Art was engaged a search of the self-identification during the general interwar crisis of European modernism and the renaissance of Mexican culture based on national roots. The New Deal art politics was developing public art as an effective resource for creature the image of a new America and Americans.

Arnautoff's career in California in the middle 1930s is formed in the field of monumental art. His murals reflected the social and economic order of the American society, which include needs in realistic art form and modern themes. The "transplantation" of American identity to the Russian artist occurred during his professional self-determination. A solidarity with the trends of the time allowed an involving of the young muralist in American life and it's ideals. The works of this period is a convincing example for how the personal expressive language developed in unison of the American art mainstream: interest in the experience of Mexican muralism, a bet on realistic art, and general understanding of the social role of art and artist.

"City Life" is the famous Arnautoff's work, the key composition in the mural complex of the Memorial Coit Tower. The image of city center became the quintessence of the personal author's experience in which muralist trying on the American identity of the artist. The composition is organized around the crossroads of Montgomery and Washington streets, the informal artistic center of the 1920s and 1930s. Arnautoff gave self-portrait features to the one of the central characters. Artist depict himself in the epicenter of American city life, he appears as one of the participants of Western modern society. Arnautoff's hero balances between the internal being inside the composition and the apartness of the outside observer. This effect is well illustration of the "split consciousness" [10. P.61] of personality of the artist, which determined his border status throughout whole life.

Integration of the Russian origin artist into the international scene started during his studies (in Mariupol, Harbin, San Francisco, Mexico City). The subsequent "overcoming of national isolation" [8. P.16], including through social activity, has allowed to strengthen ties with local art community. Looking at the world with "Russian eyes" 1, Victor Arnautoff used "optics", proposed by American social realism. In the 1930s, the "American" component dominated in the artist's life and work. This effect was short-lived, and the new attribute of the personality wasn't appropriated for a long. In 1963 the artist returned to the USSR, and received Soviet citizenship. However, despite the new status, Arnautoff continued to perceive in Homeland as the American.

\section{References}

1. Ivanenko, Yu.M. (2007) Viktor Arnautov. Zhizn'i tvorchestvo [Victor Arnautoff. Life and work]. St. Petersburg: SO LO SFK.

2. Leykind, O.L. \& Severyukhin, D.Ya. (1994) Khudozhniki russkoy emigratsii (1917-1941) [Artists of the Russian emigration (1917-1941)]. St. Petersburg: Chernyshev. 
3. Ivanenko, Yu.M. (2009) Zhizn' i tvorchestvo khudozhnika Viktora Arnautova [The life and work of the artist Victor Arnautoff]. In: Krasikova, L.V. et al. Deyateli amerikanskoy kul'tury iz Rossiyskoy imperii [The personalities of American culture from the Russian Empire]. St. Petersburg: Palace Editions. pp. 19-31.

4. Hailey, G. (1936) California Art Research. Vol. 20. San Francisco: [s.n.].

5. Lee, A.W. (1999) Painting on the Left. Diego Rivera, Radical Politics, and San Francisco's Public Murals. Berkeley: University of California Press.

6. Lombardi, S.W. (1984) Politics and Humanism in the Depression Era Frescoes of Victor Arnautoff. MA Thesis. Berkeley: University of California.

7. Cherny, R.W. (2017) Victor Arnautoff and the Politics of Art. Chicago: University of Illinois Press.

8. Severyukhin, D. (2003) Russkaya khudozhestvennaya emigratsiya. 1917-1939 [Russian Artistic Emigration. 1917-1939]. St. Petersburg: N.I. Novikov.

9. Smith, H. (2011) The Monkey Block: The Art Culture of the New Deal in San Francisco Bay Area. [Online] Available from: http://www.foundsf.org/index.php?title=The_Monkey_Block. (Accessed: 21st July 2017).

10. Galeeva, T.A. (2009) Dzhon Grekhem (Ivan Dombrovskiy) i abstraktnoe iskusstvo Ameriki 1930-kh godov [John Graham (Ivan Dombrovsky) and the abstract art of America in the 1930s]. In: Krasikova, L.V. et al. Deyateli amerikanskoy kul'tury iz Rossiyskoy imperii [The personalities of American culture from the Russian Empire]. St. Petersburg: Palace Editions. pp.61-65.

11. Indych-López, A. (2009) Muralism without walls: Rivera, Orozco and Siqueiros in The United States, 1927-1940. Pittsburgh: University of Pittsburgh Press.

12. Lucie-Smith, E. (1985) Art on the 1930s. The Age of Anxiety. New York: Rizzoli International publications.

13. Bustard, B.I. (1997) A New Deal for the Arts. Seattle: University of Washington Press.

14. Zakheim, M.J. (2009) Coit Tower San Francisco. It's History and Art. San Francisco: Volcano Press.

15. Smithsonian Institution. (n.d.) Victor Mikhail Arnautoff papers. Archive of American Art, Smithsonian Institution. 3429-3430.

16. O’Connor, F.V. (1987) La influencia de Diego Rivera en el arte de los Estados Unidos durante los años treinta y posteriors [The influence of Diego Rivera on the art of the United States during the thirties and later]. In: Rivera, D. Retrospectiva [Retrospective]. México, D.F.: Ministerio de Cultura, Dirección General de Bellas Artes y Archivos, Centro Nacional de Exposiones. pp. 167-194.

17. Chegodaev, A.D. (1976) Iskusstvo Soedinennykh Shtatov Ameriki. 1675-1975. Zhivopis'. Arkhitektura. Skul'ptura. Grafika [The Art of the United States of America. 1675-1975. Painting. Architecture. Sculpture. Graphic Arts]. Moscow: Iskusstvo.

18. The State Museum of Fine Arts. (1959) Vystavka proizvedeniy amerikanskogo iskusstva [Exhibition of Works of American Art]. Moscow: State Museum of Fine Arts. 